\title{
First report of asthma prevalence in Afghanistan using international standardized methods
}

M.H. Bemanin, ${ }^{1}$ M. Fallahpour, ${ }^{7}$ S. Arshi, ${ }^{1}$ M. Nabavi, ${ }^{1}$ T. Yousofi ${ }^{2}$ and A. Shariatifar ${ }^{2}$

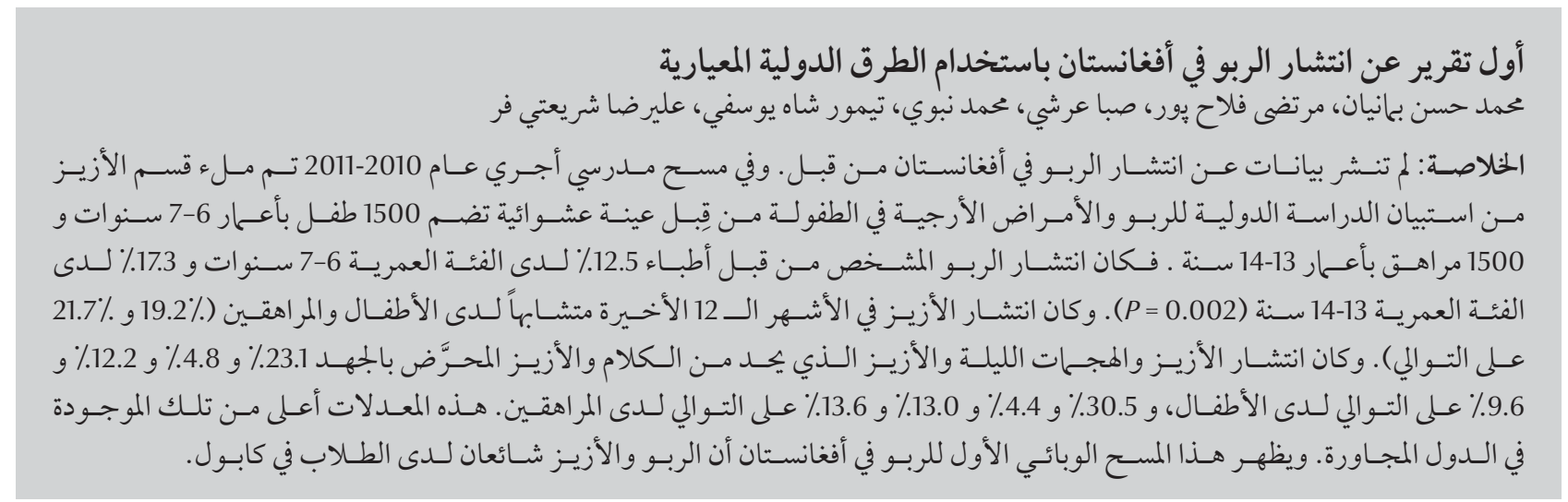

ABSTRACT No data on the prevalence of asthma in Afghanistan have been published before. In a school-based survey in 2010-2011 the wheezing section of the International Study of Asthma and Allergies in Childhood (ISAAC) questionnaire was completed by a random sample of 1500 children aged 6-7 years and 1500 adolescents aged 13-14 years old. The prevalence of physician-diagnosed asthma was $12.5 \%$ in 6 -7-year-olds and $17.3 \%$ in 13-14-year-olds $(P=0.002)$. The prevalence of wheeze in the last 12 months was similar in children and adolescents $(19.2 \%$ and $21.7 \%$ respectively). The prevalence of ever wheezing, night attacks, speech-limiting wheeze and exercise-induced wheeze was $23.1 \%, 4.8 \%, 12.2 \%$ and $9.6 \%$ respectively in children and $30.5 \%, 4.4 \%$, $13.0 \%$ and $13.6 \%$ respectively in adolescents. These rates are higher than those in neighbouring countries. This first epidemiological survey of asthma in Afghanistan shows that asthma and wheezing are common in Kabul students.

\section{Premier rapport sur l'asthme en Afghanistan utilisant des méthodes internationales normalisées}

RÉSUMÉ Aucune donnée sur la prévalence de l'asthme en Afghanistan n'a encore été publiée. Dans une enquête en milieu scolaire de 2010 à 2011, la partie sur les sibilances du questionnaire International Study of Asthma and Allergies in Childhood (ISAAC) a été remplie par un échantillon aléatoire de 1500 enfants âgés de 6 à 7 ans et de 1500 adolescents âgés de 13 à 14 ans. La prévalence du diagnostic d'asthme posé par un médecin était de $12,5 \%$ chez les enfants de 6 à 7 ans et de 17,3\% chez les adolescents de 13 à 14 ans ( $P=0,002)$. La prévalence des sibilances au cours de 12 mois précédents était similaire chez les enfants et chez les adolescents $(19,2 \%$ et $21,7 \%$, respectivement). La prévalence des sibilances, des crises nocturnes, des sibilances limitant la parole et d'une respiration sifflante induite par l'exercice était de $23,1 \%, 4,8 \%, 12,2 \%$ et $9,6 \%$, respectivement chez les enfants et de $30,5 \%, 4,4 \%, 13,0 \%$ et 13,6\% respectivement chez les adolescents. Ces pourcentages sont supérieurs à ceux des pays voisins. La première enquête épidémiologique sur l'asthme en Afghanistan révèle que l'asthme et les sibilances sont fréquents chez les élèves de Kaboul. 


\section{Introduction}

Recurrent wheezing, cough or breathlessness are the main symptoms for a diagnosis of asthma in children $(1,2)$, but due to the variable nature of asthma symptoms it is recommended to perform clinical assessments for the diagnosis of asthma (3). Clinical examinations are costly, however, and questionnaires are preferred in epidemiological studies (4). For this purpose, the International Study of Asthma and Allergies in Childhood (ISAAC) was conducted in 1990 to maximize the value of epidemiological studies of asthma and allergic diseases. ISAAC established a standardized method that facilitated international collaboration and increased its reliability with the establishment of a protocol that is used worldwide $(5,6)$. Many studies are performed in different regions throughout the world according to the ISAAC protocol or simply by using the standard questionnaires.

Afghanistan has one of the poorest public health systems in the world, with widely varying quality of health care between urban and rural areas. Decades of war has destroyed the health and education systems in this country. These conflicts make it difficult to establish statistical and census systems, so the available statistics of population, literacy rate, birth rate and other data are just estimates. The United Nations Children's Fund (UNICEF) estimates for Afghanistan for 2012 were a total population of 29824500 with 16317000 aged under 18 years and 4964400 aged under 5 years (7). Health care is funded mainly by outside sources such as the European Union, World Bank and United States Agency for International Development, and it seems that improving the statistics using epidemiological surveys and determining the prevalence of diseases can be a useful guide for better management of this global assistance.

It is well known that the prevalence of asthma has been increasing in many regions of the world during recent decades (8), but unfortunately there are no published data about the prevalence of asthma in Afghanistan. Therefore, the aim of this study was to determine the prevalence of asthma in Afghan children and adolescents using the ISAAC questionnaire for asthma and wheezing.

\section{Methods}

\section{Study setting and sampling}

Two separate systems of education exist in Afghanistan: an older system that is a religious based and the modern system. In the government-funded academic system, children attend primary school for 6 years followed by middle school for 3 years and high school for 3 years, starting from the age of 6-7 years. Although education is free and compulsory, primary school participation was $62.9 \%$ for males and $46.4 \%$ for females in 2008-2012 and secondary school participation was $42.8 \%$ for males and $21.1 \%$ for females in 2008-12 according to UNICEF estimates (7).

All schools are separate for boys and girls at all grades. Between September 2010 and May 201120 different primary and secondary schools in the modern education system ( 5 boys and 5 girls primary, 5 boys and 5 girls secondary schools) were selected randomly in different areas of the city (north, south, east and west) but we could only obtain permission from 15 schools from 15 areas of Kabul ( 5 boys and 4 girls primary and 4 boys and 2 girls secondary schools). Participants were selected randomly from among students in these schools. If a child's parents did not wish to cooperate with the interviewers, the student was excluded and another student from the same school was selected. For the boys, 1640 students were selected to participate ( 810 in the primary and 830 in the secondary schools) and 1500 were successfully enrolled (750 in the primary and 750 in the secondary schools). We selected 2100 girls (960 in the primary and 1140 in the secondary schools) and 1500 of them completed the consent form and the questionnaire (750 in the primary and 750 in the secondary schools). The low response rate for girls was because many parents refused to answer the questionnaire.

\section{Data collection}

The ISAAC standard questionnaire comprises 3 sections related to the prevalence and severity of wheezing, rhinitis and eczema respectively. In this study, we only used the wheezing questionnaire. We did not register Afghanistan in ISAAC and only used the questionnaires. As the majority of Afghan people speak Persian, we used the Persian version of the questionnaire which has been translated and validated in previous studies $(9,10)$.

Questions about age, sex, weight and height were completed first. Then respondents completed questions about history of wheezing at any time in the past and any attacks of wheezing in the last 12 months. If the answer was negative, respondents were asked whether they had a history of asthma ever diagnosed by a physician, a history of wheezing during exercise during the last 12 months or a history non-productive cough during the last 12 months. If their answer was positive, they were asked about the frequency of wheezing attacks, and any history of wheezing that disturbed sleep or wheezing that limited speech during the last 12 months.

For children, the questionnaire was completed by parents, while adolescents completed the questionnaires themselves. All parents were informed about the study and gave written consent. The study was approved by the ethics committee of Shahid Sadoughi University of Medical Sciences.

\section{Data analysis}

The chi-squared test was used to compare the relative frequency between groups. The level of significance was considered as $P<0.05$. All analyses were 
performed with SPSS, version 16 . The data were transcribed to a database and the frequency of affirmative answers to each question was analysed according to age and sex.

\section{Results}

A total of 3000 students were enrolled in this study: 1500 (750 females and 750 males) aged 6-7 years (children) and 1500 (750 females and 750 males) aged 13-14 years old (adolescents).

The prevalence of asthma diagnosed by a physician was $12.5 \%$ in 6-7-yearolds and $17.3 \%$ in $13-14$-year-olds and this was a significant difference $(P=$ 0.002 ) (Table 1). There were no significant differences between the sexes in the prevalence of physician-diagnosed asthma in children (12.9\% and $12.1 \%$ in boys and girls respectively, $P=0.64$ ) but there was a significant difference in adolescents (19.3\% and $15.2 \%$ of boys and girls respectively, $P=0.034$ ).

Wheezing during the last 12 months was reported by $19.2 \%$ of children and $21.7 \%$ of adolescents, with no significant difference $(P=0.116)$ (Table 1). The prevalence of wheeze in the last 12 months was $20.8 \%$ and $17.6 \%$ in boys and girls respectively in children $(P=$ $0.116)$ and $26.4 \%$ and $17.1 \%$ in boys and girls respectively in adolescents $(P$ $=0.001$ ), which showed a significant difference between the sexes only in adolescents.
The prevalence of lifetime history of wheezing was $23.1 \%$ in children and $30.5 \%$ in adolescents (Table 2). One or more night-time attacks of wheezing in a month was reported by $4.8 \%$ of children and $4.4 \%$ of adolescents, and $10.2 \%$ of children and $13.0 \%$ of adolescents suffered from night-time non-productive cough (Table 2). The prevalence of speech-limiting wheezing in children and adolescents was $12.2 \%$ and $13.0 \%$ respectively and wheezing during physical activity was reported for $9.6 \%$ of children and $13.6 \%$ of adolescents.

\section{Discussion}

The prevalence of asthma has been determined in many studies worldwide and the results of ISAAC have reported asthma prevalences ranging from $1.6 \%$ to $36.8 \%$ in different countries $(3,5,8)$. In the present study the prevalence of physician-diagnosed asthma in Afghan students in Kabul was $12.5 \%$ in children aged 6-7 years and $17.3 \%$ in adolescents aged 13-14 years. Because our survey was the first to determine the prevalence of asthma in the Afghan population, we cannot compare our findings with previous data from the country. However, we can confirm a higher prevalence of asthma in Afghanistan compared with neighbouring countries in Asia. The mean prevalence of asthma is $13.4 \%$ in Iranian children (10,11),3.3\% in Indian children (12) and 6\% in Pakistani adolescents aged 13-14 years (13).

Afghanistan has been in war during the last two decades, and many infectious diseases including tuberculosis and gastrointestinal infestations are endemic in the country. Szema reported an increased prevalence of asthma and occupational respiratory symptoms in United States soldiers deployed to Afghanistan and highlighted the role of so-called "burn pits". He explained that due to the lack of incinerators in Afghanistan, garbage is burned in open pits, leading to toxic aerosolized particulate matter from burning plastics, medical wastes and so on (14). According to the hygiene hypothesis, asthma and atopic diseases decrease in frequency in such conditions (15) but despite this our study using the ISAAC questionnaire showed a higher prevalence of childhood asthma than in neighbouring countries.

Our data found that the prevalence of a positive history of wheezing, which is an important factor for diagnosing asthma, was $19.2 \%$ in children and $21.7 \%$ in adolescents. These figures are comparable to other parts of the world, where the prevalence of ever wheezing varies from $4.1 \%$ to $32.1 \%$ (16). These differences could be related to different levels of knowledge about asthma among health practitioners and the general population or to the geographical and climatic situation of Kabul (17). Kabul is located in the desert with a

\begin{tabular}{|c|c|c|c|c|c|c|c|}
\hline \multirow[t]{2}{*}{ Disease/age group } & \multicolumn{2}{|c|}{$\begin{array}{c}\text { Total } \\
(n=1500)\end{array}$} & \multicolumn{2}{|c|}{$\begin{array}{c}\text { Males } \\
(n=750)\end{array}$} & \multicolumn{2}{|c|}{$\begin{array}{l}\text { Females } \\
(n=750)\end{array}$} & \multirow[t]{2}{*}{$P$-value } \\
\hline & No. & $\%$ & No. & $\%$ & No. & $\%$ & \\
\hline \multicolumn{8}{|l|}{ Asthma ever } \\
\hline $6-7$ years & 188 & 12.5 & 97 & 12.9 & 91 & 12.1 & 0.64 \\
\hline 13-14 years & 259 & 17.3 & 145 & 19.3 & 114 & 15.2 & 0.034 \\
\hline \multicolumn{8}{|c|}{ Wheezing in last 12 months } \\
\hline $6-7$ years & 288 & 19.2 & 156 & 20.8 & 132 & 17.6 & 0.116 \\
\hline $13-14$ years & 326 & 21.7 & 198 & 26.4 & 128 & 17.1 & $<0.001$ \\
\hline
\end{tabular}




\begin{tabular}{|c|c|c|c|c|c|c|c|}
\hline \multirow[t]{2}{*}{ Disease/age group } & \multicolumn{2}{|c|}{$\begin{array}{c}\text { Total } \\
(n=1500)\end{array}$} & \multicolumn{2}{|c|}{$\begin{array}{c}\text { Males } \\
(n=750)\end{array}$} & \multicolumn{2}{|c|}{$\begin{array}{l}\text { Females } \\
(n=750)\end{array}$} & \multirow[t]{2}{*}{$P$-value } \\
\hline & No. & $\%$ & No. & $\%$ & No. & $\%$ & \\
\hline \multicolumn{8}{|l|}{ Wheezing ever } \\
\hline 6-7 years & 347 & 23.1 & 182 & 24.2 & 165 & 22.0 & 0.298 \\
\hline $13-14$ years & 458 & 30.5 & 250 & 33.3 & 208 & 27.7 & 0.019 \\
\hline \multicolumn{8}{|c|}{ Night attacks of wheezing } \\
\hline 6-7 years & 72 & 4.8 & 38 & 5.0 & 34 & 4.5 & 0.629 \\
\hline $13-14$ years & 66 & 4.4 & 31 & 4.1 & 35 & 4.6 & 0.615 \\
\hline \multicolumn{8}{|c|}{ Speech-limiting wheezing } \\
\hline 6-7 years & 183 & 12.2 & 98 & 13.0 & 85 & 11.3 & 0.305 \\
\hline $13-14$ years & 195 & 13.0 & 95 & 12.6 & 100 & 13.3 & 0.701 \\
\hline \multicolumn{8}{|c|}{ Exercise-induced wheezing } \\
\hline 6-7 years & 144 & 9.6 & 81 & 10.8 & 63 & 8.4 & 0.115 \\
\hline 13-14 years & 204 & 13.6 & 121 & 16.1 & 83 & 11.0 & 0.004 \\
\hline \multicolumn{8}{|l|}{ Night cough } \\
\hline 6-7 years & 153 & 10.2 & 87 & 11.6 & 66 & 8.8 & 0.073 \\
\hline 13-14 years & 195 & 13.0 & 88 & 11.7 & 107 & 14.2 & 0.145 \\
\hline
\end{tabular}

dry and hot climate and strong winds throughout the year. This is likely to result in high levels of suspended dust that might produce respiratory symptoms such as wheezing, and this can explain why wheeze is very common in Afghan children.

There were no significant differences in physician-diagnosed asthma between the sexes, but wheezing in the last the 12 months was reported in significantly more of the boys than the girls: $20.8 \%$ versus $17.6 \%$ of male and female children respectively and $26.4 \%$ versus $17.1 \%$ of male and female adolescents respectively.
We asked questions only about asthma without considering allergic rhinitis and eczema and this could be regarded as a very important limitation of the study. Another major limitation was the 3-year delay between conducting the study and reporting the results. One reason for the delay was the difficult conditions of Afghanistan and the challenges of doing research for our Afghan colleagues. However, to our best knowledge there is no other study investigating asthma in Afghanistan and this is the first report of asthma prevalence in this part of the world.

\section{Conclusions}

In this study, we determined the prevalence of asthma in Afghanistan children and adolescents aged 6-7 and 13-14 years for the first time. It seems that the prevalence of asthma in Afghanistan is higher than in neighbouring countries.

\section{Acknowledgements}

\section{Funding: None.}

Competing interests: None declared.

\section{References}

1. Cornish RP, Henderson J, Boyd AW, Granell R, Van Staa T, Macleod J. Validating childhood asthma in an epidemiological study using linked electronic patient records. BMJ Open. 2014;4(4):e005345. PMID:24760357

2. Global strategy for asthma management and prevention [Internet]. Global Initiative for Asthma (http://www.ginasthma. org/uploads/users/files/GINA_Report_2011.pdf, accessed 12 January 2014).

3. Pekkanen J, Pearce N. Defining asthma in epidemiological studies. Eur RespirJ. 1999 Oct;14(4):951-7. PMID:10573248

4. Remes ST, Pekkanen J, Remes K, Salonen RO, Korppi M. In search of childhood asthma: questionnaire, tests of bronchial hyperresponsiveness, and clinical evaluation. Thorax. 2002 Feb;57(2):120-6. PMID:11828040
5. Solé D, Camelo-Nunes IC, Wandalsen GF, Mallozi MC. Asthma in children and adolescents in Brazil: contribution of the International Study of Asthma and Allergies in Childhood (ISAAC). Rev Paul Pediatr. 2014 Mar;32(1):114-25. PMID:24676199

6. Pearce N. ISAAC-background and methods. Eur Respir J. 1996;9 Suppl 23:410s.

7. Country information: Afghanistan [Internet]. United Nations Children Fund (http://www.unicef.org/infobycountry/afghanistan.html, accessed 12 January 2014).

8. Yangzong Y, Shi Z, Nafstad P, Håheim LL, Luobu O, Bjertness E. The prevalence of childhood asthma in China: a systematic review. BMC Public Health. 2012;12:860. PMID:23050953 
9. Humanitarian health action: Afghanistan [Internet]. World Health Organization (http://www.who.int/hac/donorinfo/ afg/en/index1.html, accessed 12 January 2014).

10. Zobeiri M. Prevalence, risk factors and severity of asthma symptoms in children of Kermanshah, IRAN: ISAAC phase I, II. Acta Med Iran. 2011;49(3):184-8. PMID:21681708

11. Entezari A, Mehrabi Y, Varesvazirian M, Pourpak Z, Moin M. A systematic review of recent asthma symptom surveys in Iranian children. Chron Respir Dis. 2009;6(2):109-14. PMID:19411572

12. Pal R, Barua A. Prevalence of childhood bronchial asthma in India. Annals of Tropical Medicine and Public Health. 2008;1:73-5.

13. Yusuf MO. Systems for the management of respiratory disease in primary care-an international series: Pakistan. Prim Care RespirJ. 2009 Mar;18(1):3-9. PMID:18587512

14. Szema AM. Occupational lung diseases among soldiers deployed to Iraq and Afghanistan. Occup Med Health Aff. 2013; 1:117. PMID: 24443711
15. Solis Soto MT, Patiño A, Nowak D, Radon K. Prevalence of asthma, rhinitis and eczema symptoms in rural and urban school-aged children from Oropeza Province, Bolivia: a crosssectional study. BMC Pulm Med. 2014;14:40. PMID:24612913

16. Montefort S, Lenicker HM, Caruna S, Agius Muscat H; International Study of Asthma and Allergies in Childhood. Asthma, rhinitis and eczema in Maltese 13-15 year-old schoolchildrenprevalence, severity and associated factors [ISAAC]. Clin Exp Allergy. 1998 Sep;28(9):1089-99. PMID:9761012

17. Narayana PP, Prasanna MP, Narahari SR, Guruprasad AM. Prevalence of asthma in school children in rural India. Ann Thorac Med. 2010 Apr;5(2):118-9. PMID:20582180 